\title{
The Association of Cardio-Ankle Vascular Index and Ankle-Brachial Index with Macroangiopathy in Patients with Type 2 Diabetes Mellitus
}

\author{
Hirokatsu Niwa ${ }^{1}$, Kiyohiko Takahashi², Midori Dannoura ${ }^{2}$, Kazuno Oomori², Arina Miyoshi², \\ Toshihiro Inada ${ }^{3}$ and Hideaki Miyoshi ${ }^{2,4}$ \\ ${ }^{1}$ Niwa Diabetic Care Clinic, Sapporo, Japan \\ ${ }^{2}$ Department of Rheumatology, Endocrinology and Nephrology, Faculty of Medicine and Graduate School of Medicine, Hokkaido \\ University, Sapporo, Japan \\ ${ }^{3}$ IBEC Co., Ltd., Osaka, Japan \\ ${ }^{4}$ Division of Diabetes and Obesity, Faculty of Medicine and Graduate School of Medicine, Hokkaido University, Sapporo, Japan
}

Aims: This study elucidates the association of macroangiopathy development in type 2 diabetes patients with various arteriosclerosis risk factors (ARFs) and results of cardio-ankle vascular index (CAVI) and ankle-brachial pressure index $(\mathrm{ABI})$.

Methods: The correlation between current and past macroangiopathy development, with ARFs or CAVI/ABI data, was retrospectively analyzed using multivariate logistic regression in 816 patients with type 2 diabetes at a single center. C-statistics combining some independent variables selected using the stepwise method were evaluated.

Results: CAVI was significantly correlated with macroangiopathies, including coronary artery disease (CAD), arteriosclerosis obliterans (ASO), and stroke with odds ratios (OR) of 1.20, 1.22, and 1.19, respectively. ABI significantly correlated with ASO and stroke with respective OR of 13.6 and 2.47, but not with CAD. Areas under the receiver operating characteristic curves (ROCs) revealed the accuracy of detecting ASO and stroke was increased by the combination of CAVI + ABI ( 0.94 and 0.74 , respectively). However, areas under the ROC for the presence of CAD can be increased by the combination of CAVI and ARFs especially including dyslipidemia.

Conclusion: CAVI/ABI and some ARFs are useful tools in daily clinical care units to identify the current and past existence of macroangiopathy in patients with type 2 diabetes, but the prediction weights using these factors were different among CAD, ASO, and stroke.

Key words: Ankle-brachial pressure index, Cardio-ankle vascular index, Macroangiopathy

\section{Introduction}

The number of diabetic patients is increasing each year. It is important for these patients to prevent concomitant development of complications by maintaining a healthy lifestyle and a good quality of life. Diabetic retinal disease, nephropathy, and neuropathy are the three major complications and are caused by microangiopathy ${ }^{1)}$.
Other important complications are coronary artery disease (CAD), stroke, and arteriosclerosis obliterans (ASO), which are categorized to macroangiopathy ${ }^{2)}$. Because arteriosclerosis gradually and silently worsens over time, and the incidence of related complications is markedly higher in diabetic patients, early and strict control of related arteriosclerosis risk factors (ARFs) is important to prevent macroangiopathy, particularly in diabetic patients ${ }^{2-4)}$. Predicting the development of mac- 
roangiopathy with high probability is, however, difficult during daily medical treatment of patients in clinics.

The cardio-ankle vascular index (CAVI $)^{5)}$ and ankle-brachial pressure index $(\mathrm{ABI})^{6}$ have been widely used to evaluate arterial stiffening and arterial stenosis/obstruction, and both indices are considered useful for preventing macroangiopathies. Although many reports have suggested that CAVI and ABI are useful diagnostic tools for macrovascular complications ${ }^{7-9)}$, there are few reports on the correlation between these indices and the development of each macroangiopathy while taking ARFs into account. Many clinicians need prediction methods for macroangiopathy based on a combination of ABI, CAVI, and ARFs, especially those in small clinics without large diagnostic instruments such as tomographic (CT) and magnetic resonance imaging (MRI). That is, simple, non-invasive, reproducible, lowcost vascular function tests may better predict macroangiopathies in small clinics.

In this study, we have focused on how to predict the concomitant development of macroangiopathy in diabetic patients in a single clinical unit without using CT, MRI, or other diagnostic special equipment. Thus, we investigated the relationship between current and past development of macroangiopathies and ARFs, CAVI, or ABI.

\section{Methods}

\section{Study Design and Patients}

This was a single-center, retrospective, observational study approved by the Ethical Committee of Sapporo Medical Association (Hokkaido, Japan) and the institutional review board of Niwa Diabetic Care Clinic (Hokkaido, Japan). The contents of the present study were posted in the clinic. A total of 816 patients (females, 293, males, 523) with type 2 diabetes, who visited the clinic from March to May in 2016 and underwent CAVI and ABI examinations, were enrolled in this study. The data at the most recent visit before the end of study were collected for each patient. The patients' backgrounds, including the current and past development of cardiovascular events, and ARFs such as dyslipidemia (DL, LDL cholesterol: $140 \mathrm{mg} / \mathrm{dL} \leq$, HDL cholesterol: $40 \mathrm{mg} / \mathrm{dL}>$, triglyceride: $150 \mathrm{mg} /$ $\mathrm{dL}<$ ), hypertension (HT, systolic blood pressure: $\geq 140$ $\mathrm{mmHg}$, diastolic blood pressure: $\geq 90 \mathrm{mmHg}$ ), hyperuricemia $(\mathrm{HU}, 7.0 \mathrm{mg} / \mathrm{dL}<)$, or smoking habit at the time of diagnosis, were determined from their clinical records. CAVI with a normal range of $<8.0$ was determined by using a small sized vascular screening system (VS1500AE, Fukuda Denshi Co., Ltd., Tokyo Japan), which is available in almost clinics in Japan ${ }^{7,8)}$. ABI
Table 1. Patient background characteristics

\begin{tabular}{|c|c|}
\hline Factor & Mean \pm SD \\
\hline Age (year) & $59.3 \pm 11.6$ \\
\hline Body weight (kg) & $67.7 \pm 13.9$ \\
\hline BMI $\left(\mathrm{kg} / \mathrm{m}^{2}\right)$ & $25.5 \pm 4.0$ \\
\hline HbA1c (\%) & $7.87 \pm 1.82$ \\
\hline $\mathrm{SBP}(\mathrm{mmHg})$ & $143.3 \pm 19.4$ \\
\hline $\mathrm{DBP}(\mathrm{mmHg})$ & $89.3 \pm 10.7$ \\
\hline Heart rate & $68.1 \pm 14.3$ \\
\hline ABI & $1.12 \pm 0.10$ \\
\hline CAVI & $9.2 \pm 1.8$ \\
\hline Complication & $\%{ }^{*}$ \\
\hline ASO & 3.3 \\
\hline CAD & 16.8 \\
\hline Stroke & 10.3 \\
\hline Any of macroangiopathy & 26.7 \\
\hline ARF & $\%$ * \\
\hline Dyslipidemia & 81.1 \\
\hline Hypertension & 66.9 \\
\hline Hyperuricemia & 7.0 \\
\hline Smoking ${ }^{\S}$ & 32.8 \\
\hline \multicolumn{2}{|c|}{$\begin{array}{l}n=816 ;{ }^{*} \text {, ratio of the number of patients with complications and } \\
\text { ARF; } \$ \text {, smoking history or status is unclear in one patient } \\
\text { ABI, ankle brachial pressure index; ARF, arteriosclerotic risk factor; } \\
\text { ASO, arteriosclerosis obliterans; BMI, body mass index; CAD, angina/ } \\
\text { myocardial infarction; CAVI, cardio ankle vascular index; DBP, dia- } \\
\text { stolic blood pressure; SBP, systolic blood pressure }\end{array}$} \\
\hline
\end{tabular}

was used to screen for ASO and subjects were divided into four groups according to ABI (high ankle pressure group, $>1.40$; normal group, $1.00 \leq$ but $\leq 1.40$; normal but borderline group, $0.90<$ but $<1.00$; suspected ASO group, $\leq 0.90)^{10)}$. ABI was simultaneously measured using the same equipment (VS1500AE).

Macroangiopathy including ASO, CAD, and stroke was diagnosed by specialists and recorded in the medical history. ASO is defined by the absence of pulse of dorsalis pedis, posterior tibial artery, and/or popliteal artery, and the presence of intermittent claudication. CAD includes myocardial infarction, coronary artery stenosis (more than 75\%), or history of coronary intervention, and stable angina. Stroke includes brain hemorrhage, cerebral infarction, and transient ischemic attack.

The correlation between each macroangiopathy and the patients' backgrounds (ARFs, CAVI, and ABI) was investigated.

\section{Statistical Analysis}

The correlation between the ARFs or the measurement results of CAVI and ABI and the develop- 
Table 2. Correlation of each factor with the presence of any of macroangiopathy

\begin{tabular}{lccc}
\hline \multirow{2}{*}{ Factor } & \multicolumn{2}{c}{ Current and past onset of } & macroangiopathy \\
\cline { 2 - 3 } & \multicolumn{2}{c}{ None } & Pvalue \\
\cline { 2 - 3 } Age & $57.4 \pm 11.6$ & $64.4 \pm 9.7$ & $<0.001$ \\
ABI & $1.13 \pm 0.08$ & $1.08 \pm 0.13$ & $<0.001$ \\
CAVI & $8.9 \pm 1.6$ & $10.1 \pm 2.1$ & $<0.001$ \\
SBP & $140.9 \pm 18.4$ & $149.9 \pm 20.5$ & $<0.001$ \\
DBP & $88.9 \pm 10.8$ & $90.4 \pm 10.6$ & 0.068 \\
Heart rate & $67.4 \pm 14.7$ & $70.1 \pm 12.9$ & 0.019 \\
HbA1c & $7.93 \pm 1.90$ & $7.69 \pm 1.55$ & 0.091 \\
Body weight & $68.2 \pm 14.8$ & $66.5 \pm 10.9$ & 0.123 \\
BMI & $25.6 \pm 4.1$ & $25.4 \pm 3.6$ & 0.520 \\
\hline
\end{tabular}

Each value represents the mean \pm standard deviation $(\mathrm{SD})$.

$\mathrm{ABI}$, ankle brachial pressure index; BMI, body mass index; CAVI, cardio ankle vascular index; DBP, diastolic blood pressure; HbA1c, hemoglobin A1c; SBP, systolic blood pressure;

$\S$, Macroangiopathy includes arteriosclerosis obliterans, angina/myocardial infarction, or stroke. The number of macroangiopathies was 0 for "None" and 1 to 3 for "Exist".

(No. of patients, $n=816$ )

Table 3. Correlation of the presence of each macroangiopathy and CAVI

\begin{tabular}{lcrl}
\hline Complication & $\begin{array}{c}\text { Current and past } \\
\text { existence of disease }\end{array}$ & $\begin{array}{c}\text { CAVI } \\
\text { Mean } \pm \text { SD }\end{array}$ & Pvalue $^{\S}$ \\
\hline ASO & None & $9.15 \pm 1.66$ & $<0.001$ \\
& Exist & $11.28 \pm 3.88$ & $<0.001$ \\
\hline CAD & None & $9.04 \pm 1.72$ & $<0.001$ \\
\hline Stroke & Exist & $10.12 \pm 2.00$ & \\
& None & $9.09 \pm 1.70$ & \\
\hline
\end{tabular}

ASO, arteriosclerosis obliterans; CAD, angina/myocardial infarction, CAVI, cardio ankle vascular index, ${ }^{\S}$; Welch two sample $t$-test, Number of patients: 816

ment of macroangiopathy was analyzed using the Welch two sample $t$-test and multivariate logistic regression. The stepwise procedure was used as the variable selection method. Additionally, evaluation was performed for C-statistics in which some independent variables were combined. The statistical analysis software used was R, and pROC was used as a statistical analysis package ${ }^{11)} . P$ values less than 0.05 were considered a significant difference.

\section{Results}

Overall, 816 patients were enrolled with an average age of 59.3 years, body mass index (BMI) $25.5 \mathrm{~kg} /$ $\mathrm{m}^{2}$, and the HbA1c level 7.87\% (Table 1). Twentyfour percent (196 of 816) of the patients suffered from macroangiopathy, and the incidence of CAD was the highest $(16.8 \%)$ on the patients. In most of the pres- ent cases, there was no incompatibility between the medical history of macroangiopathy and the clinical presentation/auscultation results. Among ARFs, concomitant DL was the highest (662 of 816 patients, $81.1 \%$ ), and the rates of HT and smoking were $66.9 \%$ and $32.8 \%$, respectively. The values of ABI and CAVI were $1.12 \pm 0.10$ and $9.2 \pm 1.8$, respectively. The CAVI values obtained in this study corresponded to those at the age of $64.2 \pm 15.3$ years, which was 4.9 years higher than the actual age. These results indicate that the arteries in patients with macroangiopathy were stiffer than those in patients without the disease. The ABI value for the most of the patients $(88.6 \%)$ was normal, while $9.1 \%(n=74)$ of patients were in the borderline group and 2.2\% $(n=18)$ were in the suspected ASO group. CAVI, ABI, and most of ARFs except HbAlc, body weight, and BMI were significantly correlated with macroangiopathy (Table 2). We next 


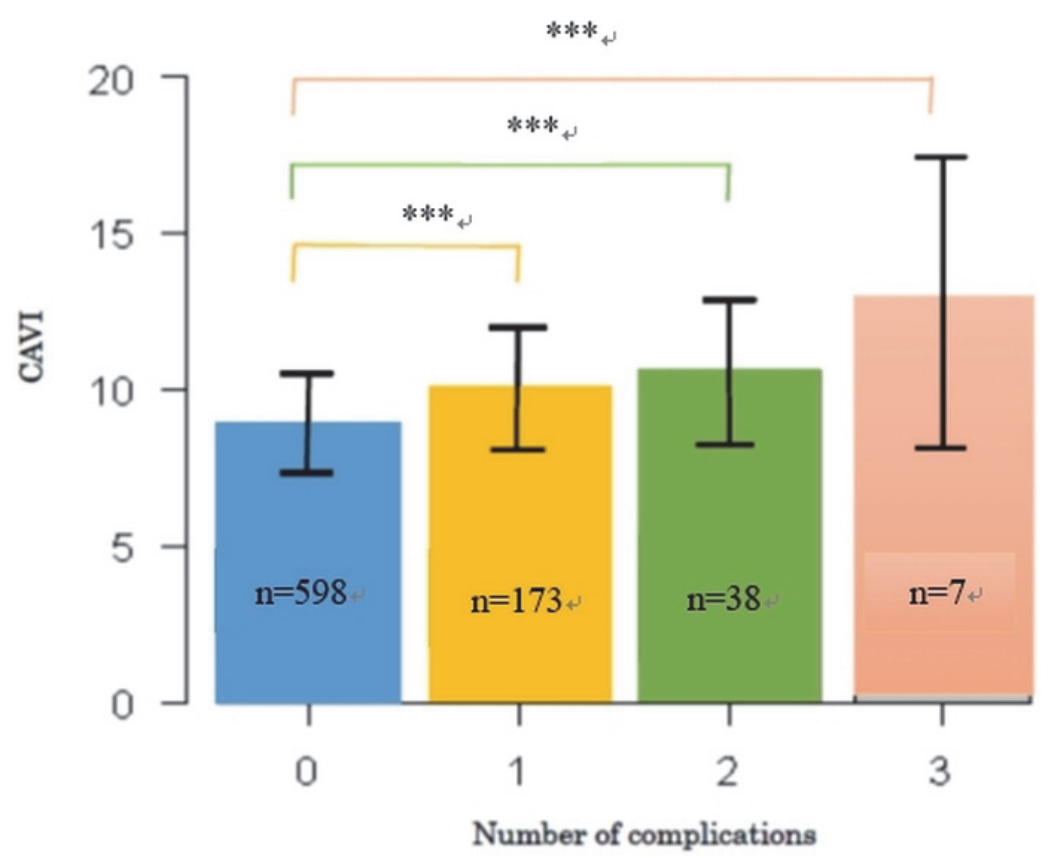

Fig. 1. Relationship between the number of the complications per patient and CAVI.

***, $P<0.001 ; n=$ number of patients; ANOVA test

investigated the correlation between the existence of each macroangiopathy and the CAVI values (Table 3). The CAVI value of patients with ASO, CAD, or stroke were significantly higher than those of the patients without macroangiopathy $(P<0.001)$. Additionally, patients with a greater number of macroangiopathies resulted in a significantly higher CAVI compared to patients with fewer macroangiopathies (Fig. 1).

Finally, we analyzed the data using multivariate logistic regression analysis to elucidate how important the CAVI and ABI measurements are for each type of macroangiopathy (Table 4). ABI $\leq 0.9$ was the highest risk factor associated with ASO and stroke with respective odds ratios (OR) of 426 and $4.26(P<0.001)$, and the ABI threshold $(>0.9$ but $<1.0)$ was also significantly associated with those macroangiopathies. However, $A B I$ was not an independent variable for CAD. DL, SBP, DBP, male sex, and CAVI were the independent variables, and DL was the largest risk factor for CAD with an OR of 1.91. HT was a significant risk factor for stroke with an OR of 2.00, and male sex was a significant risk factor for ASO and $\mathrm{CAD}$ with respective ORs of 6.05 and 1.77. A higher CAVI value was a significant risk factor for all macroangiopathies (ASO, CAD, and stroke; Tables 3 and 4).

ROCs of various independent variables for macroangiopathy were examined (Fig.2). Areas under the ROCs of ABI, CAVI, and CAVI + ABI for the exis- tence of ASO were 0.92, 0.70, and 0.94, respectively. Similarly, stroke could be predicted from ABI and CAVI results. Areas under the ROCs of CAVI, ABI, and CAVI + ABI were $0.68,0.60$, and 0.74 , respectively. Accuracy for area under the ROCs was increased by combining variables. Areas under the ROCs of CAVI, $\mathrm{CAVI}+\mathrm{HT}+$ age + male sex, and CAVI $+\mathrm{HT}+$ age + male sex $+\mathrm{DL}$ were $0.68,0.70$, and 0.71 , respectively, for the existence of CAD.

\section{Discussion}

We investigated the association of diabetic macroangiopathies with CAVI/ABI levels or various ARFs. Reports have described the association of CAVI/ABI, and ARFs with macroangiopathies in patients with or without diabetes ${ }^{12-19)}$. In those studies, the investigators mainly evaluated the usefulness of ABI/CAVI and some ARFs to diagnose macroangiopathies and to determine disease conditions. In the present study, we investigated the 'quantitative' importance of the CAVI/ABI or ARFs to predict future macroangiopathy development in patients with type 2 diabetes. Previous reports and the present study showed that the macroangiopathy development could be detected by CAVI, ABI, and most ARFs (except for the risk factor of increased body mass). The reason for no relationship with increased body mass is equivocal, but it could be related to post- 
Table 4. Association of the ARFs and the macroangiopathy measurement results

\begin{tabular}{|c|c|c|c|c|}
\hline Complication Risk factor & $\begin{array}{c}\text { Partial regression } \\
\text { coefficient } \pm S E\end{array}$ & Odds ratio & $\begin{array}{c}95 \% \text { confidence } \\
\text { interval }\end{array}$ & $P$ value \\
\hline \multicolumn{5}{|l|}{ ASO } \\
\hline ABI classification $[\mathrm{T} .<1.0$ but $>0.9]$ & $2.61 \pm 0.61$ & 13.6 & 4.16 to 44.70 & $<0.001$ \\
\hline Male (female) & $1.80 \pm 0.86$ & 6.05 & 1.11 to 32.9 & $<0.05$ \\
\hline CAVI & $0.20 \pm 0.10$ & 1.22 & 1.00 to 1.49 & $<0.05$ \\
\hline \multicolumn{5}{|l|}{ CAD } \\
\hline Hyperlipidemia & $0.64 \pm 0.28$ & 1.91 & 1.10 to 3.31 & $<0.05$ \\
\hline Male & $0.57 \pm 0.23$ & 1.77 & 1.14 to 2.76 & $<0.05$ \\
\hline CAVI & $0.18 \pm 0.06$ & 1.20 & 1.07 to 1.35 & $<0.01$ \\
\hline Age & $0.03 \pm 0.01$ & 1.03 & 1.01 to 1.05 & $<0.01$ \\
\hline Hypertension & $0.69 \pm 0.32$ & 2.00 & 1.06 to 3.77 & $<0.01$ \\
\hline CAVI & $0.19 \pm 0.06$ & 1.19 & 1.05 to 1.35 & $<0.001$ \\
\hline Age & $0.03 \pm 0.01$ & 1.03 & 1.01 to 1.06 & $<0.001$ \\
\hline \multicolumn{5}{|l|}{ Any of macroangiopathy } \\
\hline ABI classification $[\mathrm{T} . \leq 0.9]$ & $3.03 \pm 0.84$ & 20.7 & 3.98 to 10.8 & $<0.001$ \\
\hline ABI classification $[\mathrm{T} .<1.0$ but $>0.9]$ & $1.11 \pm 0.28$ & 3.02 & 1.75 to 5.23 & $<0.001$ \\
\hline Hypertension & $0.75 \pm 0.21$ & 2.13 & 1.40 to 3.23 & $<0.001$ \\
\hline Male & $0.64 \pm 0.20$ & 1.91 & 1.29 to 2.81 & $<0.01$ \\
\hline CAVI & $0.26 \pm 0.06$ & 1.29 & 1.14 to 1.47 & $<0.001$ \\
\hline Age & $0.04 \pm 0.01$ & 1.04 & 1.02 to 1.06 & $<0.001$ \\
\hline
\end{tabular}

ABI, ankle brachial pressure index; ASO, arteriosclerosis obliterans; CAVI, cardio ankle vascular index; SBP, systolic blood pressure; SE, standard error

prandial hyperglycemia resulting from reduced insulin secretion levels or relatively easier ectopic visceral fat depositing because of a reduced ability to store fat subcutaneously in the Asian population ${ }^{20-22)}$.

The present study demonstrated that CAVI resulted in a significantly high value in patients with macroangiopathy complications (Table 3); the increase depended on the number of macroangiopathies (Fig. 1). Although ABI values were likely to be more reliable than CAVI to predict the existence of ASO and stroke, the combination values of CAVI and ABI provided better diagnostic efficiency and gave most accurate prediction for ASO and stroke but not CAD (Table 4, Fig. 2).

The degree of involvement of HT in stroke and ASO found in this study was compatible with previous epidemiological studies performed in Japan and throughout the world ${ }^{23-26}$. Large-scale prospective studies, including Japan Diabetes Complications Study and United Kingdom Prospective Diabetes Study, have shown that a lipid abnormality is most likely involved in the development of $\mathrm{CAD}^{27,28)}$, and treatment of
$\mathrm{DL}$ is useful as a primary and secondary prevention for cardiovascular events ${ }^{29}, 30$ ). In this study, 662 of 816 patients $(81.1 \%)$ had DL, and the highest OR was obtained for the complication of DL in the multivariate analysis in CAD.

In clinical practice, clinicians frequently measure CAVI and ABI at the same time in Japan, but rarely combine them because both methods have independent evaluation criteria. In this study, we measured CAVI and ABI simultaneously and examined whether future macroangiopathy development can be predicted by combining with appropriate ARFs. As a result, we can show the evaluation's effectiveness by combining multiple inspection data. Thus, this study demonstrated that the ABI and CAVI values, accompanied by classical risk factors, may help clinicians in a general internal medicine clinic to refer patients to the appropriate hospital or division to prevent developing or aggravating complications. Appropriately predicting complications using a non-invasive and low-cost examination will reduce patients' mental and economic burdens. 

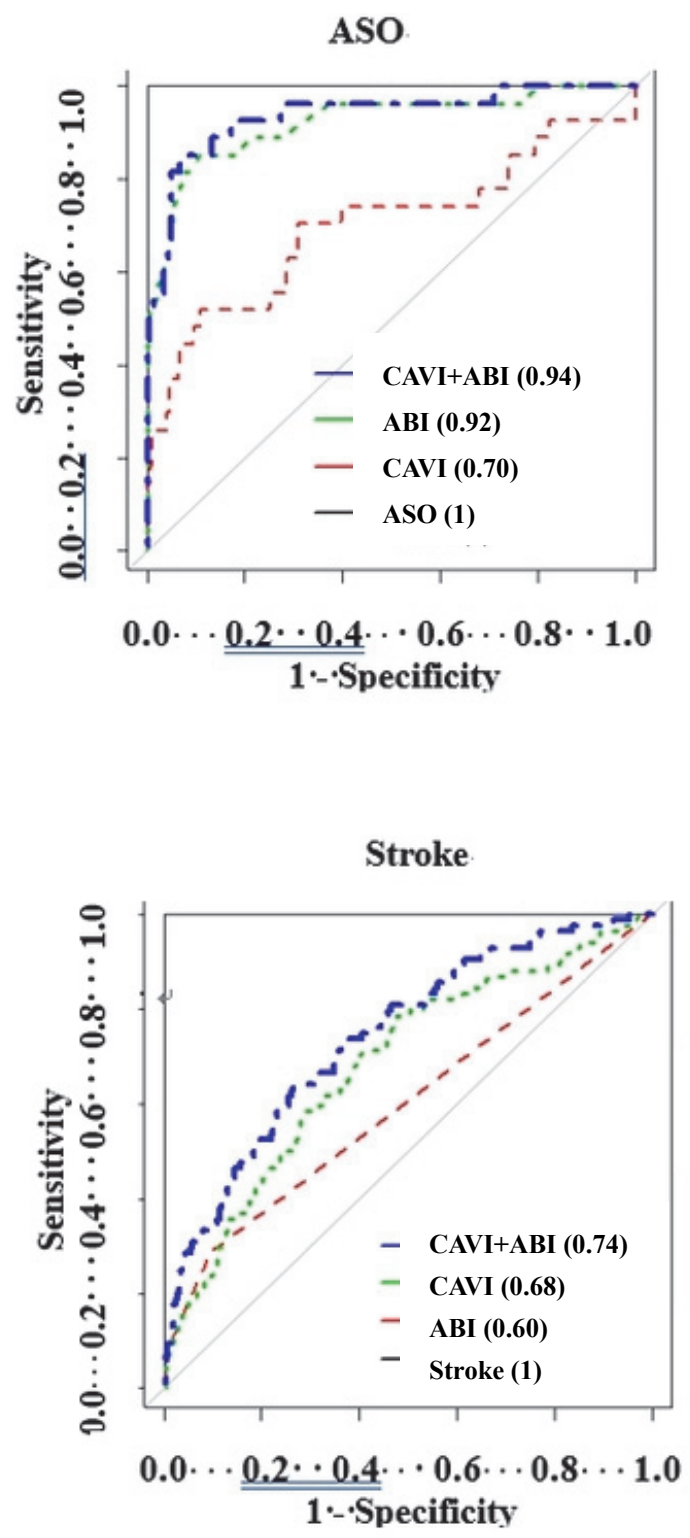
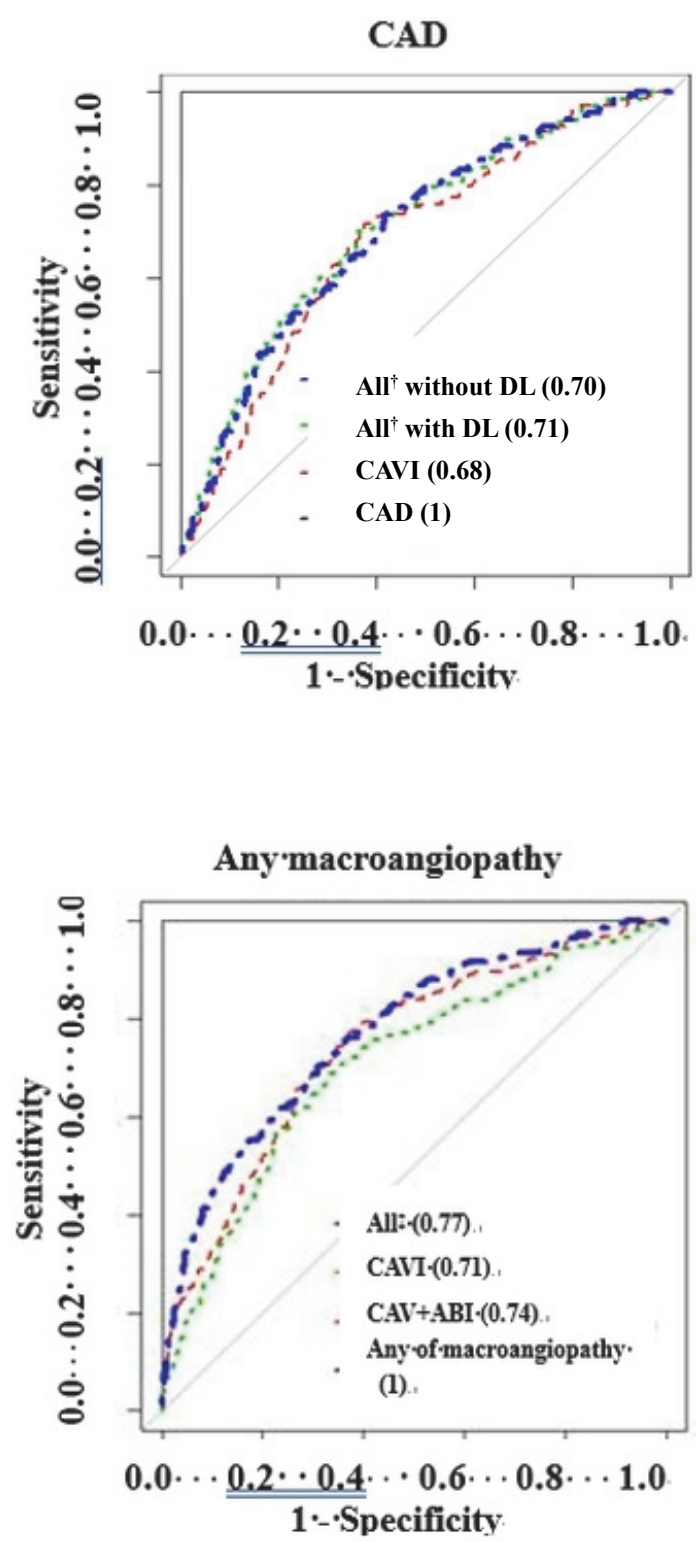

Fig. 2. ROCs of various independent variables for ASO, CAD, stroke, and the presence of any macroangiopathy

Figures in parentheses represent area under the curve. ABI, ankle-brachial pressure index; ASO, arteriosclerosis obliterans; CAVI, cardio-ankle vascular index; HbA1c, hemoglobin A1c; DL, dyslipidemia; HT, hypertension; $\mathrm{MI}$, myocardial infarction; ${ }^{\dagger}, \mathrm{CAVI}+\mathrm{ABI}+$ age $+\mathrm{HT}+\mathrm{HbA1c},{ }^{\ddagger}, \mathrm{CAVI}+\mathrm{ABI}+$ male + age $+\mathrm{HT}$

The major limitation of this study is the authors may have missed a macroangiopathy diagnosis. Although macroangiopathy often progresses asymptomatically, its existence in the present study was based on review of the patients' medical records. Some invasive examinations, such as coronary angiography, computed tomography, or magnetic resonance angiography, are required to diagnose the macroangiopathy more accurately. Another limitation was this cross-sectional study at a single clinic, and the ARFs were already treated using medication, and thus, they were almost controlled. Although it is difficult to perform this trial prospectively in practice, a multicenter prospective study for a long duration would confirm these results. There is a possibility that Mönckeberg type arteriosclerosis exists especially in the lower limb arteries in DM patients whose ABI is apparently normal or high. Since this is an important point and limitation of this study, 
we should take care in the interpretation of $A B I$ data.

The results of ROCs for each independent variable and their combination provide further support for the usefulness of CAVI, ABI, and other risk factors as predictors of future development of macroangiopathy complications in patients with diabetes. In conclusion, we can predict macroangiopathy development with a high probability in routine medical care in clinics, based on data from $\mathrm{ABI}$ and CAVI, and other risk factors including male sex, age, SBP, HT, and DL.

\section{Acknowledgement}

We thank Fukuda Foundation Medical Technology for its helpful assistance and discussion. We also thank Jodi Smith, PhD, from Edanz Group (www. edanzediting.com/ac) for editing a draft of this manuscript.

\section{Sources of Funding}

This Study was supported in part by a grant from Fukuda Foundation Medical Technology.

\section{Conflict of Interest}

The authors declare no conflict of interest associated with this manuscript.

\section{References}

1) Global report on diabetes, World Health Organization, Geneva, 2016

2) Gæde P, Vedel P, Larsen N, Jensen G VH, Parving HH and Pedersen O: Multifactorial Intervention and Cardiovascular Disease in Patients with Type 2 Diabetes, N Engl J Med 2003; 348: 383-393

3) Gæde P, Andersen HL, Parving HH and Pedersen O: Effect of a Multifactorial Intervention on Mortality in Type 2 Diabetes, N Engl J Med 2008; 358: 580-591

4) Griffin SJ, Borch-Johnsen K, Davies MJ, Khunti K, Rutten GE, Sandbæk A, Sharp SJ, Simmons RK, van den Donk M, Wareham NJ and Lauritzen T: Effect of early intensive multifactorial therapy on 5-year cardiovascular outcomes in individuals with type 2 diabetes detected by screening (ADDITION-Europe): a cluster-randomized trial, Lancet 2011; 378: 156-167

5) Shirai K, Utino J, Otsuka K, Takata M: A novel blood pressure-independent arterial wall stiffness parameter; cardio-ankle vascular index (CAVI). J Atheroscler Thromb. 2006; 13: 101-107

6) Norgren L, Hiatt WR, Dormandy JA, Nehler MR, Harris KA, Fowkes FGR, on behalf of the TASC II (Inter-Society Consensus for the Management of Peripheral Arterial disease) Working Group. J Vasc Surg 2007; 45: Supplement 5-S67

7) Nishizawa $Y$, Shoji T, Maekawa K, Nagasue K, Okuno S,
Kim M, Emoto M, Ishimura E, Nakatani T and Miki T, Inaba M: Intima-media thickness of carotid artery predicts cardiovascular mortality in hemodialysis patients. Am J kidney Dis. 2003; 41: S76-79

8) Srinubab G, Allam A.R and Narashima R.M: Identification of Biomarkers for Type 2 Diabetes and Its Complications: A Bioinformatic Approach. Int J Biomed Sci. 2007; 3: 229-236

9) Cardiovascular disease risk factors. World Heart Federation, Home//Cardiovascular disease risk factors

10) Kajikawa M, Maruhashi T, Iwamoto $Y$, Iwamoto A, Matsumoto T, Hidaka T, Kihara Y, Chayama K, Nakashima A, Goto C, Noma K, Higashi Y: Borderline Ankle-Brachial Index Value of 0.91-0.99 is associated With Endothelial Dysfunction, Circ J 2014; 78: 1740-1745

11) Robin X, Turck N, Hainard A, Tiberti N, Lisacek F, Sanchez JC and Müller M: pROC: an open-source package for $\mathrm{R}$ and $\mathrm{S}+$ to analyze and compare ROC curves. BMC Bioinformatics. 2011, 7; 77. DOI: 10.1186/1471- 210512-77

12) Kadota $K$, Takamura N, Aoyagi $K$, Yamasaki $H$, Usa $T$, Nakazato M, Maeda T, Wada M, Nakashima K, Abe K, Takeshima F and Ozono Y: Availability of cardio-ankle vascular index (CAVI) as a screening tool for atherosclerosis. Circ J. 2008, 72: 304-308

13) Nakamura K, Tomaru T, Yamamura $S$, Miyashita $Y$, Shirai $\mathrm{K}$ and Noike $\mathrm{H}$ : Cardio-ankle vascular index is a candidate predictor of coronary atherosclerosis. Circ J. 2008, 72: 598-604

14) Wakabayashi I and Masuda $H$. Relationships between vascular indexes and atherosclerotic risk factors in patients with type 2 diabetes mellitus. Angiology. 2008, 59: $567-$ 573

15) Masugata H, Senda S, Himoto T, Murao K, Dobashi H, Kitano Y, Okuyama H, Inukai M, Hosomi N, Kohno M, Nishiyama Y, Kohno T and Gohda F: Detection of increased arterial stiffness in a patient with early stage of large vessel vasculitis by measuring cardio-ankle vascular index. Tohoku J Exp Med. 2009, 219: 101-105

16) Kotani K and Remaley A: Cardio-Ankle Vascular Index (CAVI) and its Potential Clinical Implications for Cardiovascular Disease. Cardiol Pharmacol. 2013, 2: 108

17) Otsuka K, Fukuda S, Shimada K, Suzuki K, Nakanishi K, Yoshiyama M and Yoshikawa J: Serial assessment of arterial stiffness by cardio-ankle vascular index for prediction of future cardiovascular events in patients with coronary artery disease. Hypertens Res. 2014, 37: 1014-1020

18) Gómez-Marcos MÁ, Recio-Rodríguez JI, Patino-Alonso MC, Agudo-Conde C, Gómez-Sánchez L, Gomez-Sanchez M, Rodríguez-Sanchez E, Maderuelo-Fernandez JA, García-Ortiz L; LOD-DIABETES Group: Cardio-ankle vascular index is associated with cardiovascular target organ damage and vascular structure and function in patients with diabetes or metabolic syndrome, LOD-DIABETES study: a case series report. LOD-DIABETES Group, Cardiovasc Diabetol. 2015; 14: 7

19) Gohda T, Gotoh H, Gotoh Y, Yamaguchi $S$ and Tomino Y: Association of the cardioankle vascular index and anklebrachial index with carotid artery intima media thickness in hemodialysis patients, Int J Nephrol. 2013; Article ID 401525: 5 pages, DOI: 10.1155/2013/401525. Epub 2013 
June 24

20) Takeno K, Tamura Y, Kawaguchi M, Kakehi S, Watanabe T, Funayama T, Furukawa Y, Kaga H, Yamamoto R, Kim M, Nishitani-Yokoyama M, Shimada K, Daida H, Aoki S, Taka H, Fujimura T, Sawada SS, Giacca A, Kanazawa A, Fujitani Y, Kawamori R and Watada H: Relation between insulin sensitivity and metabolic abnormalities in Japanese men with BMI of $23-25 \mathrm{~kg} / \mathrm{m}^{2}$. J Clin Endoclin Metab. 2016; 101: 3676-3684

21) Tripathy D. Carlsson M, Almgren P, Isomaa B, Taskinen MR, Tuomi T and Groop LC: Insulin secretion and insulin sensitivity in relation to glucose tolerance: lessons from the Botnia Study. Diabetes. 2000; 49: 975-980

22) Fukushima M. Suzuki $H$ and Seino $Y$ : Insulin secretion capacity in the development from normal glucose tolerance to type 2 diabetes. Diabetes Res Clin Pract. 2004; 66: $\$ 37-43$

23) Iimura O: Insulin resistance and hypertension in Japanese. Hypertens Res 1996; 19: S1-8

24) Thomas F, Benetos A and Guize L: Impaired fasting glucose, blood pressure and cardiovascular disease mortality. Hypertension 2002; 40: 458-463

25) Pechère-bertschi A, Greminger P, Hess L, Philippe J and Ferrari P: Swiss hypertension and risk factor program (SHARP): Cardiovascular risk factors management in patients with type 2 diabetes in Switzerland. Blood Pressure 2005; 14: 337-344
26) Kengne AP, Patel A, Barzi F, Jamrozik K, Lam TH, Ueshima H, Gu DF, Suh I and Woodward M: Systolic blood pressure, diabetes and the risk of cardiovascular diseases in the Asia-Pacific region, J Hypertens 2007; 25: 1205-1213

27) Sone H, Tanaka S, Tanaka S, Iimuro S, Ishibashi S, Oikawa S, Shimano H, Katayama S, Ohashi Y, Akanuma Y and Yamada N: Comparison of Various Lipid Variables as Predictors of Coronary Heart Disease in Japanese Men and Women with Type 2 Diabetes; Subanalysis of the Japan Diabetes Complications Study, Diabetes Care. 2012; 35: 1150-1157

28) Turner RC, Millns H, Neil HA, Stratton IM, Manley SE, Matthews DR and Holman RR: Risk factors for coronary artery disease in non-insulin dependent diabetes mellitus: United Kingdom Prospective Diabetes Study (UKPDS: 23), BMJ. 1998; 316: 823-828

29) de Vries FM, Denig P, Pouwels KB, Postma MJ and Hak E: Primary Prevention of Major Cardiovascular and Cerebrovascular Events with Statins in Diabetic Patients, A Meta-Analysis, Drugs 2012; 72: 2365-2373

30) de Vries FM, Kolthof J, Postma MJ, Denig P and Hak E: Efficacy of Standard and Intensive Statin Treatment for the Secondary Prevention of Cardiovascular and Cerebrovascular Events in Diabetes Patients: A Meta-Analysis, PLoS ONE 2014; 9: e111247 https://doi.org/10.1371/journal.pone.0111247 